\title{
FUNCTIONAL OUTCOME OF COMMINUTED INTRAARTICULAR DISTAL RADIUS FRACTURES TREATED WITH FRAGMENT SPECIFIC FRACTURE FIXATION
}

\author{
Mohan Ganesan1, Nirmal Mohan²
}

${ }^{1}$ Assistant Professor, Department of Orthopaedics, Govt. Kilpauk Medical College and Hospital.

2Junior Resident, Department of Orthopaedics, Govt. Kilpauk Medical College and Hospital. \begin{abstract}
BACKGROUND

Distal radius fractures are one of the most common fractures encountered in orthopaedic practice. Plate fixation of distal radius is one of the commonest modalities of treatment of distal radius fractures. This study focuses on fixation of comminuted intraarticular distal radius fractures based on the fragments involved according to Medoff classification. If the volar rim is involved, volar locking plates are used. If the dorsal wall is involved, dorsal locking plates are used. If the radial column is involved, radial plates are used. For involvement of multiple fragments, combination of plates are used. Various approaches are used for plating on different fragments. Low profile plates are used in this study to avoid soft tissue complications.

The aim of this study is to assess functional outcome of comminuted intraarticular distal radius fractures treated by fragment specific fracture fixation.

Study Centre- Govt. Kilpauk Medical College.

Study Design- Prospective study.
\end{abstract}

\section{RESULTS}

20 patients with comminuted intraarticular distal radius fractures were treated with low profile plates and were assessed with Gartland and Werley scoring system. 15 patients (75\%) had excellent results and 5 patients (20\%) had good results.

\section{CONCLUSION}

We conclude that using low profile plates for distal radius fractures gives excellent outcome and using combination of low profile plates in comminuted intraarticular distal radius fractures is a very good option.

\section{KEYWORDS}

Fragment Specific Fracture Fixation, Intraarticular Distal Radius Fractures.

HOW TO CITE THIS ARTICLE: Ganesan M, Mohan N. Functional outcome of comminuted intraarticular distal radius fractures treated with fragment specific fracture fixation. J. Evolution Med. Dent. Sci. 2018;7(05):690-696, DOI: 10.14260/jemds/2018/156

\section{BACKGROUND}

Fractures of the distal end of radius are one of the most common fractures encountered in orthopaedic practice encompassing $16 \%$ of all fractures.(1) It is the most common fracture involving the upper limb. About $50 \%$ of fractures of the distal radius involve the articular surface. The peak age groups involved are children from 5 to 14 years, males less than 50 years and females more than 60 years. Medoff classified intraarticular distal radius fractures based on the fragments involved.(2) This classification is based on the observation that fracture lines along the distal radius propagate along recurrent pathways. According to this classification, the distal radius is divided into 5 fragments (volar rim, dorsal wall, ulnar corner, radial column, central fragment).

This study focuses on fixation of comminuted intraarticular distal radius fractures based on the fragments involved according to Medoff classification. If the volar rim is involved, volar locking plates are used. If the dorsal wall is involved, dorsal locking plates are used. If the radial column is

'Financial or Other Competing Interest': None.

Submission 12-09-2017, Peer Review 12-11-2017,

Acceptance 18-11-2017, Published 29-01-2018.

Corresponding Author:

Dr. Ganesan Mohan,

D5/159, KP Towers, Arcod Road,

Vadapalani, Chennai-600026.

E-mail:dr_gmohan@yahoo.com

DOI: $10.14260 /$ jemds $/ 2018 / 156$

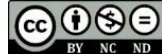

involved, radial plates are used. For involvement of multiple fragments, combinations of plates are used. Various approaches are used for plating on different fragments. Low profile plates are used in this study to avoid soft tissue complications.

\section{Aim of the Study \\ To study the functional outcome of comminuted intraarticular distal radius fractures, treated by fragment specific fracture fixation.}

\section{MATERIALS AND METHODS}

This prospective study on 'Functional outcome of intraarticular distal radius fractures, managed by fragment specific fracture fixation' was conducted in the Department of Orthopaedic Surgery, Govt. Kilpauk Medical College and Hospital, Chennai from September 2014 to July 2016 after ethical committee clearance was obtained.

\section{Inclusion Criteria}

A sample size of 20 patients were taken who satisfied the following inclusion criteria-

1. Age 18-50 years.

2. Patients $>50$ years with high functional demand.

3. Intraarticular distal radius fractures with more than $2 \mathrm{~mm}$ articular step-off.

4. $>0$ degree dorsal tilt.

5. $2 \mathrm{~mm}$ or more of radial shortening.

6. Loss of 5 degrees or more of radial inclination. 


\section{Exclusion Criteria}

1. Skeletal immaturity.

2. Extraarticular fractures.

3. Non-displaced intraarticular fractures.

4. Open fractures.

5. Pathological fractures.

6. Old fractures.

7. Associated neurovascular injuries.

\section{Radiological Evaluation}

Standard Posteroanterior and Lateral views of the involved wrist joint.

CT of the involved wrist joint.

CT and the x-rays are used to assess the morphology of the fracture, based on which the implants to be used and the surgical approach to the fracture are decided.

This study is based on Medoff classification of intraarticular distal radius fractures, where distal radius was divided into 5 fragments based on the observation that fracture lines in the distal radius tend to propagate in recurrent pathways. The goal of the treatment is to achieve perfect reduction without any intraarticular step-off, so that the patients can have excellent functional outcome and arthritis can be avoided. Hence, we approach each fracture according to its morphology and specific approaches and specific implants are used to stabilise each fragment.

\section{Implant Choice}

- Volar fragment fracture- $2.4 \mathrm{~mm}$ volar LCP.

- Radial column fracture- $2.4 \mathrm{~mm}$ straight LCP/ K-wire fixation.

- $\quad$ Dorsal fragment fracture- $2.4 \mathrm{~mm}$ dorsal T-LCP.

- If multiple fragments are involved, double plating of involved columns are done.

\section{Implants Used}

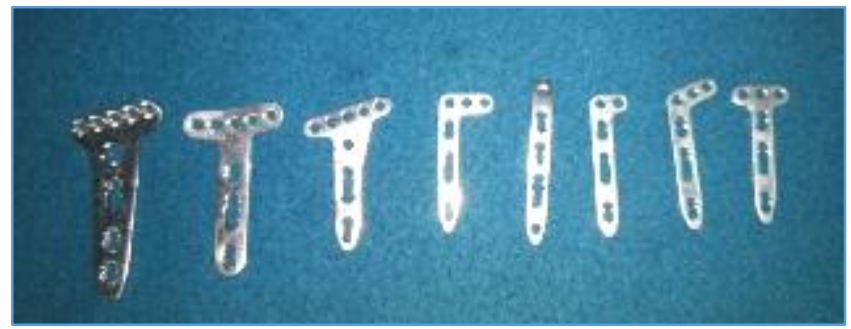

\section{From Left to Right}

- Volar T-oblique plate.

- Volar straight T plate.

- Dorsal T-oblique plate.

- L plate.

- Radial styloid straight plate.

- Short L plate.

- L-oblique plate.

- $\quad$ Dorsal T plate.

\section{Instruments Used}

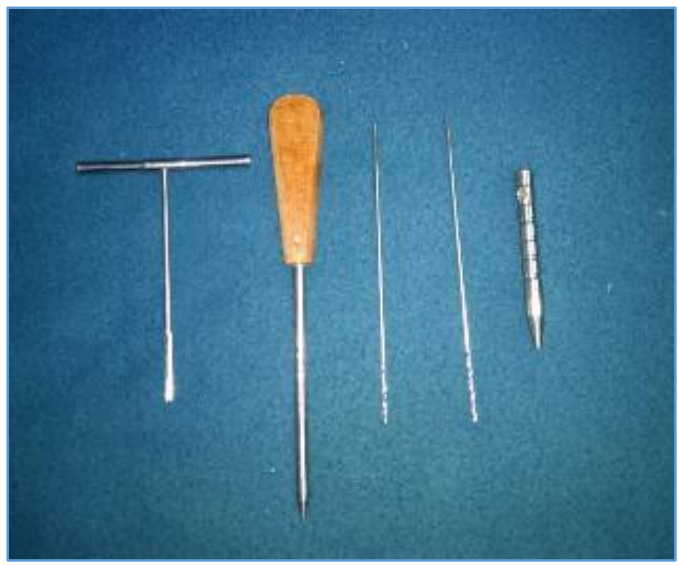

\section{From Left to Right}

- $2 \mathrm{~mm}$ tap.

- $2.4 \mathrm{~mm}$ screw driver.

- $2 \mathrm{~mm}$ drill bit (2 in nos.).

- $\quad$ Locking sleeve.

\section{Surgical Technique}

After regional anaesthesia, patient in supine position with the arm in a radiolucent forearm table and under strict aseptic precaution parts were painted and draped upto midarm.

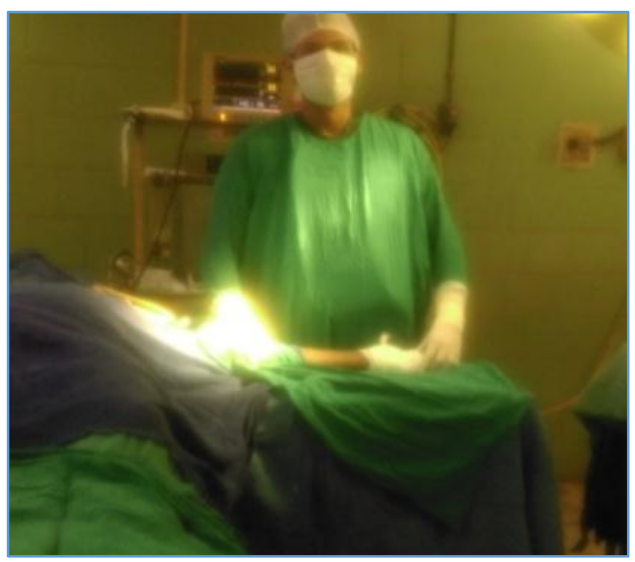

The C-arm is draped with sheets and is positioned perpendicular to the fracture table for further use during surgery to check for articular reduction and plate positioning.

\section{Surgical Approach}

- Volar fragment.

- Modified Henry's approach is used to reach volar fragment.

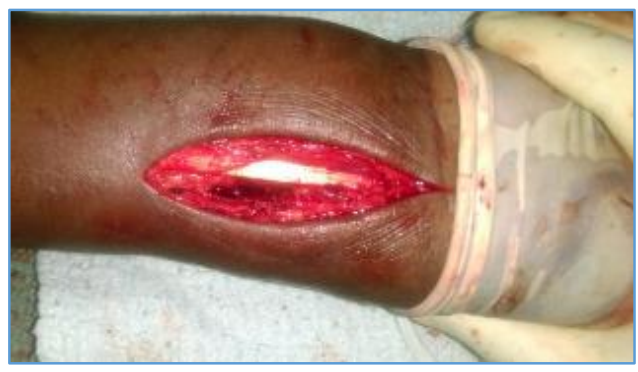

Figure 1. Skin Incision is made along the Radial Border of Flexor Carpi Radialis Tendon 


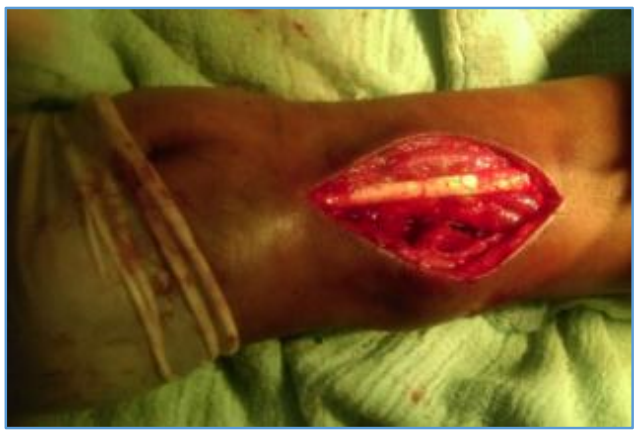

Figure 2. Incision is Deepened between Flexor Carpi Radialis and the Radial Artery

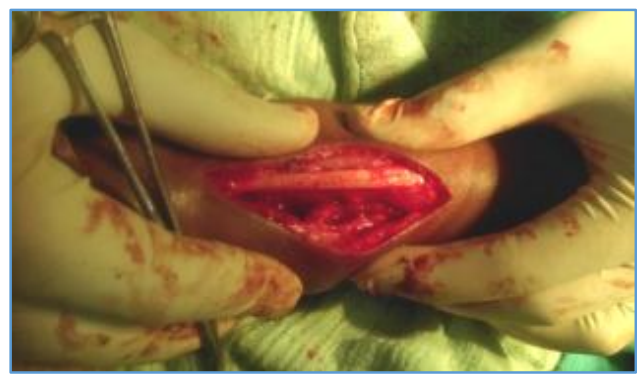

Figure 3. The Pronator Quadratus Muscle is Elevated using an L Shaped Incision
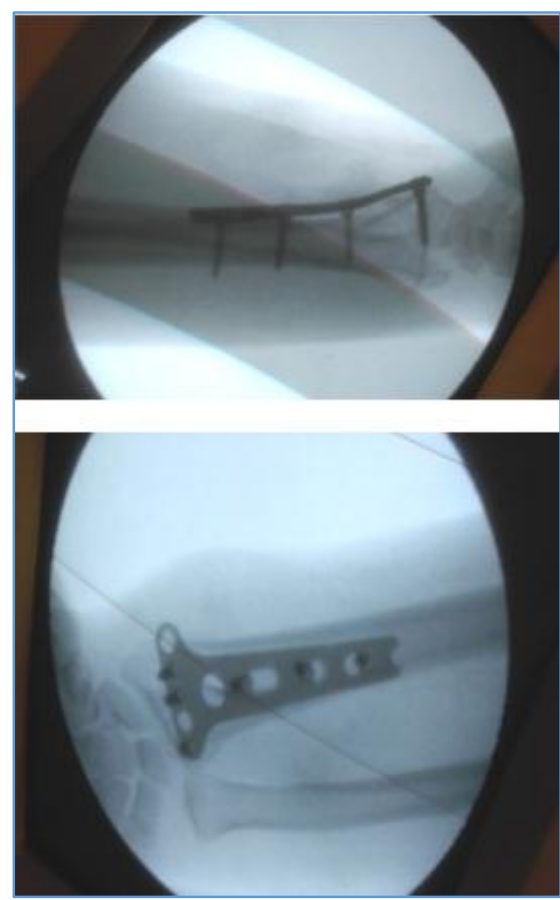

Figure 4. The Fracture is Reduced under C-Arm Guidance and Fixed with a Plate which is Checked under C-Arm

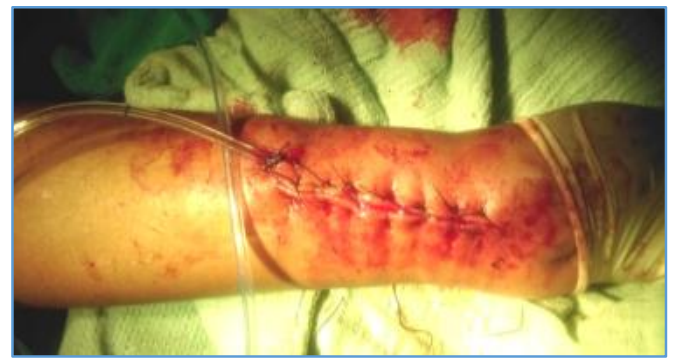

Figure 5. Once Plate Positioning and Fixation are Confirmed with adequate C-Arm views Wound is Washed and Closed over a Suction Drain
Radial Fragment



A Straight Skin Incision is made over the Anatomical Snuff Box with the Distal and Proximal extent as necessary. The Superficial Cutaneous Branch of the Radial Nerve is Identified and Protected

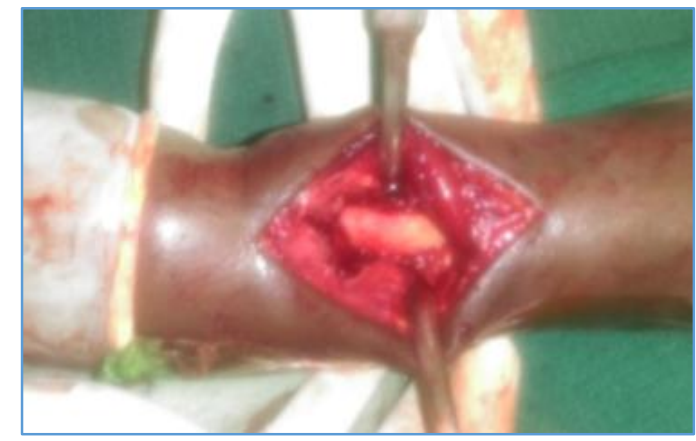

The First and Second Dorsal Compartments are Elevated and Radial Styloid is Exposed

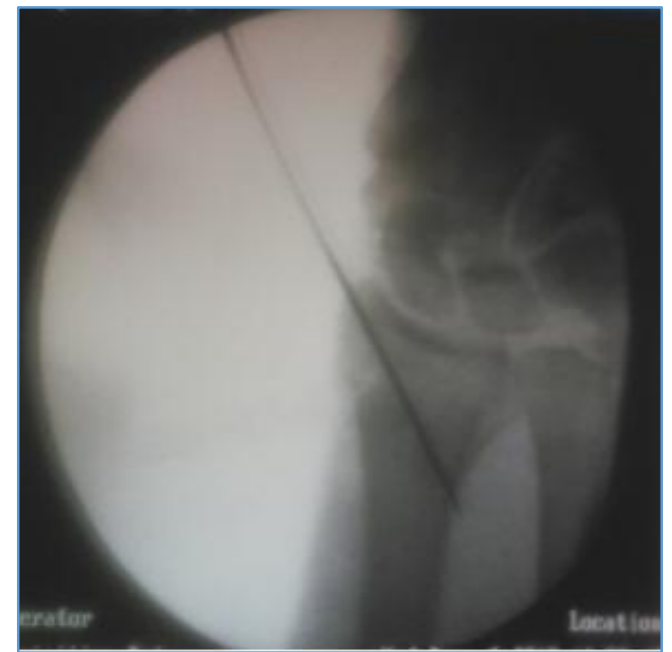

The Fracture is Provisionally Fixed under C-Arm Guidance with K-Wires

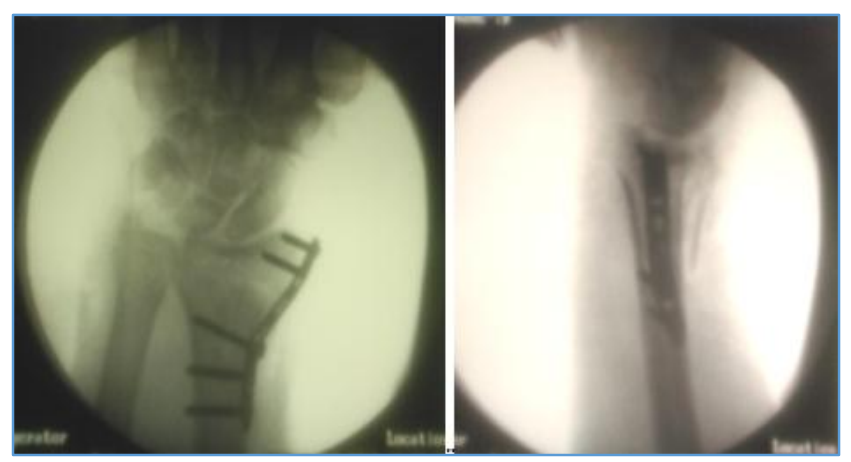

Once Provisional Fixation is Obtained Fracture is Fixed with a Straight Lateral Plate after Plate Positioning is confirmed under C-Arm Guidance 


\section{Dorsal Fragment}

The intermediate and radial columns may be approached through a single dorsal skin incision. The skin incision is put in line with the third metacarpal with the proximal and distal extents as necessary.

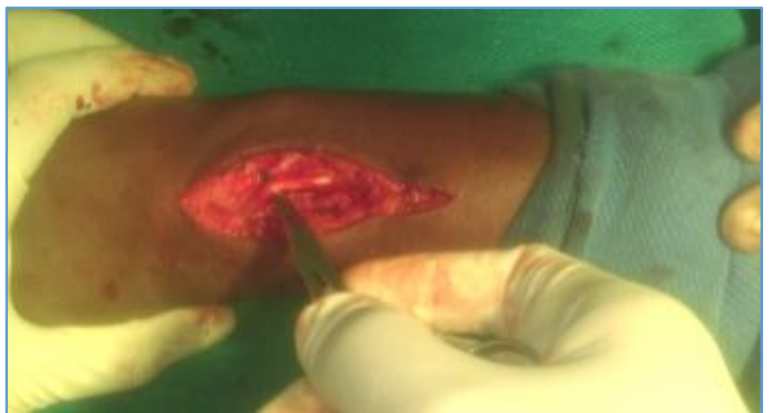

The Third Extensor Compartment is Opened in Line with the Extensor Pollicis Longus Tendon. The Distal Part of Extensor Retinaculum is maintained, so that the EPL Tendon can still Glide over the Thumb

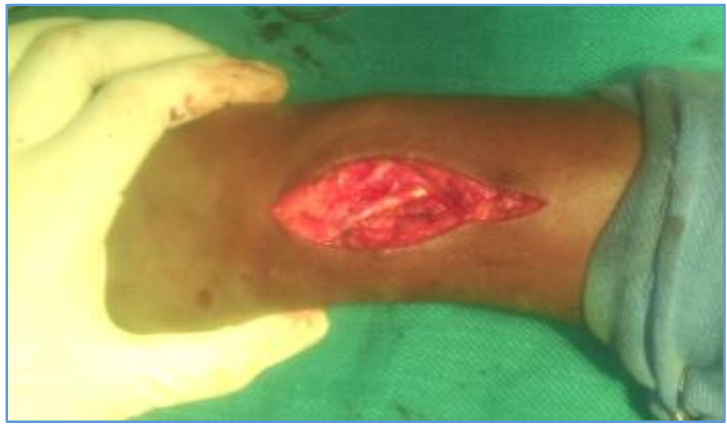

The Fourth Extensor Compartment is Elevated

Subperiosteally for Adequate Exposure of the Fracture Site

\section{Postoperative Care}

Strict limb elevation was maintained for all patients postoperatively. In the immediate postoperative period, adequate pain relief was given in consultation with anaesthetists. Intravenous antibiotics were given till the $2^{\text {nd }}$ postoperative day, following which oral antibiotics were started.

Postoperative $\mathrm{x}$-ray was taken on the $1^{\text {st }}$ postoperative day. Check dressings were done on the $2^{\text {nd }}$ and $5^{\text {th }}$ postoperative day. Drain removal was done on the $2^{\text {nd }}$ postoperative day. Suture removal was done on the $12^{\text {th }}$ postoperative day.

Patients were reviewed at 3 weeks, 6 weeks, 3 months, 6 months and 1 year, and subsequent $\mathrm{x}$-rays were taken to assess union. Finger and elbow mobilisation was started immediately after surgery. Wrist mobilisation was started 1 week postoperatively as pain tolerated. Strengthening exercises were started 6 weeks postoperatively.

\begin{tabular}{|c|c|}
\hline IV Antibiotics & $\begin{array}{c}\text { First Five Days after } \\
\text { Surgery }\end{array}$ \\
\hline Check dressings & $2^{\text {nd }}$ and $5^{\text {th }}$ postop days \\
\hline Suture removal & $12^{\text {th }}$ postop day \\
\hline Finger and elbow mobilisation & Immediate postop \\
\hline Wrist mobilisation & 1 week postop \\
\hline Strengthening exercises & 6 weeks postop \\
\hline
\end{tabular}

Outcome Assessment

Functional outcome was assessed using Gartland and Werley scoring system.

\section{CASE REPORTS}

Case 1.
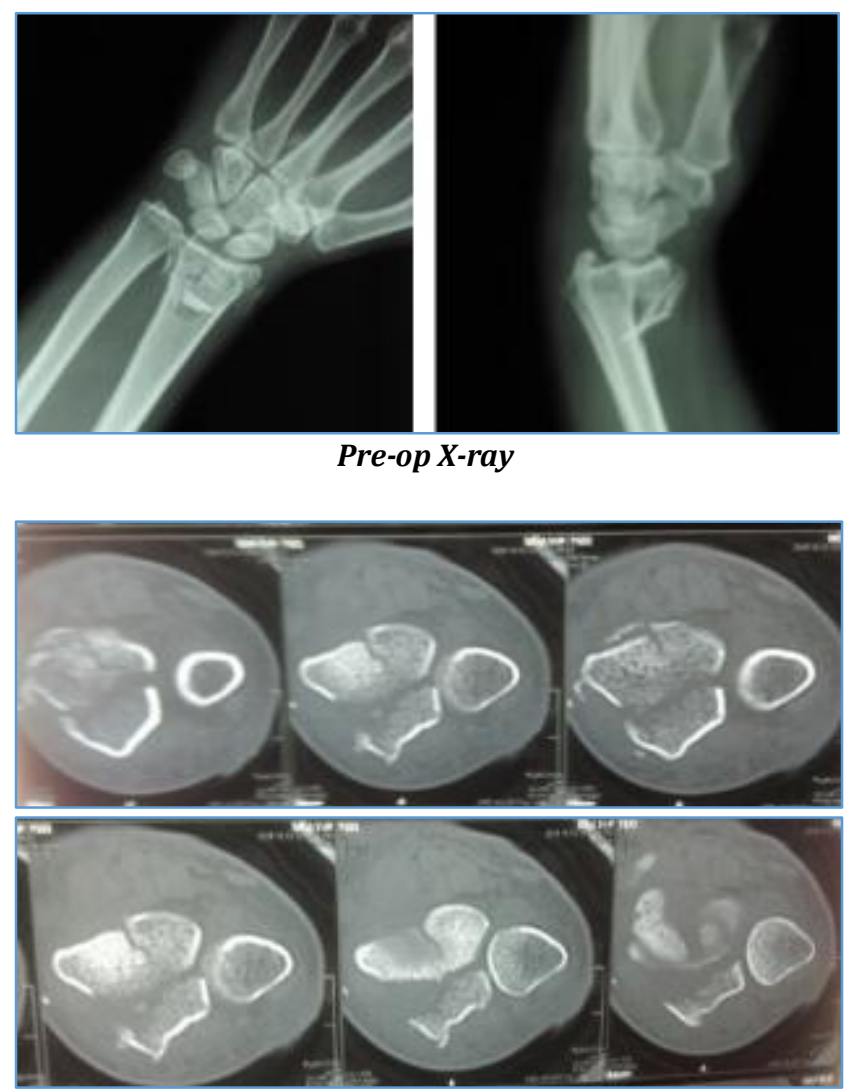

Pre-op CT

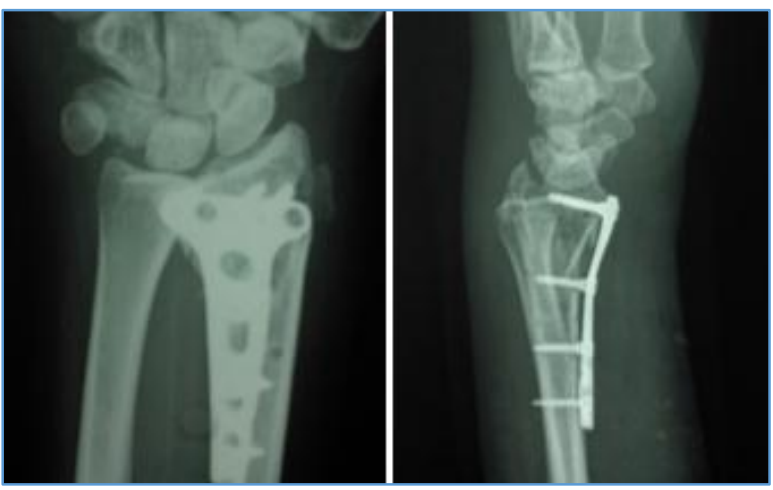

Immediate Post-op X-ray

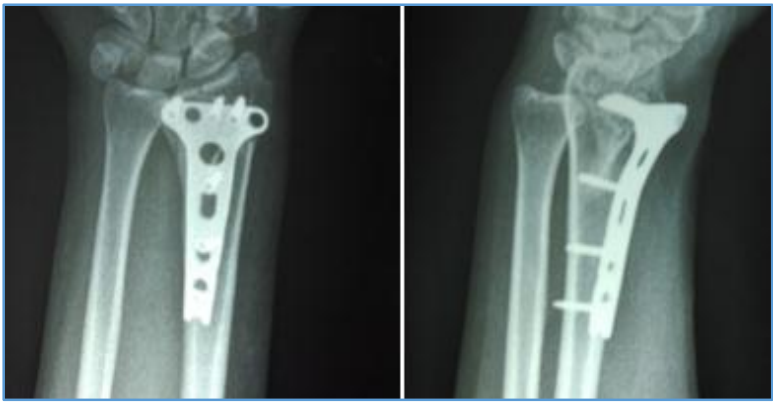

3 Months Followup 


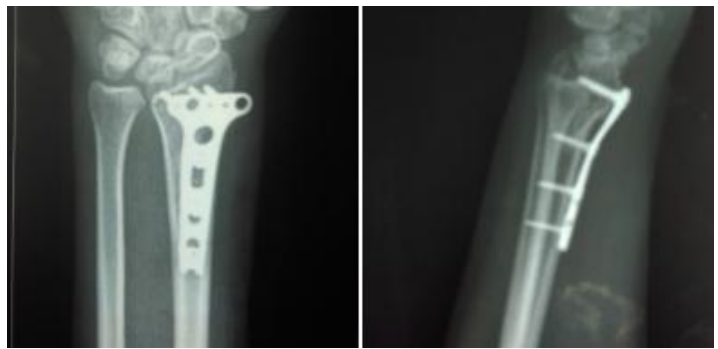

6 Months Followup

\section{Clinical Pictures}
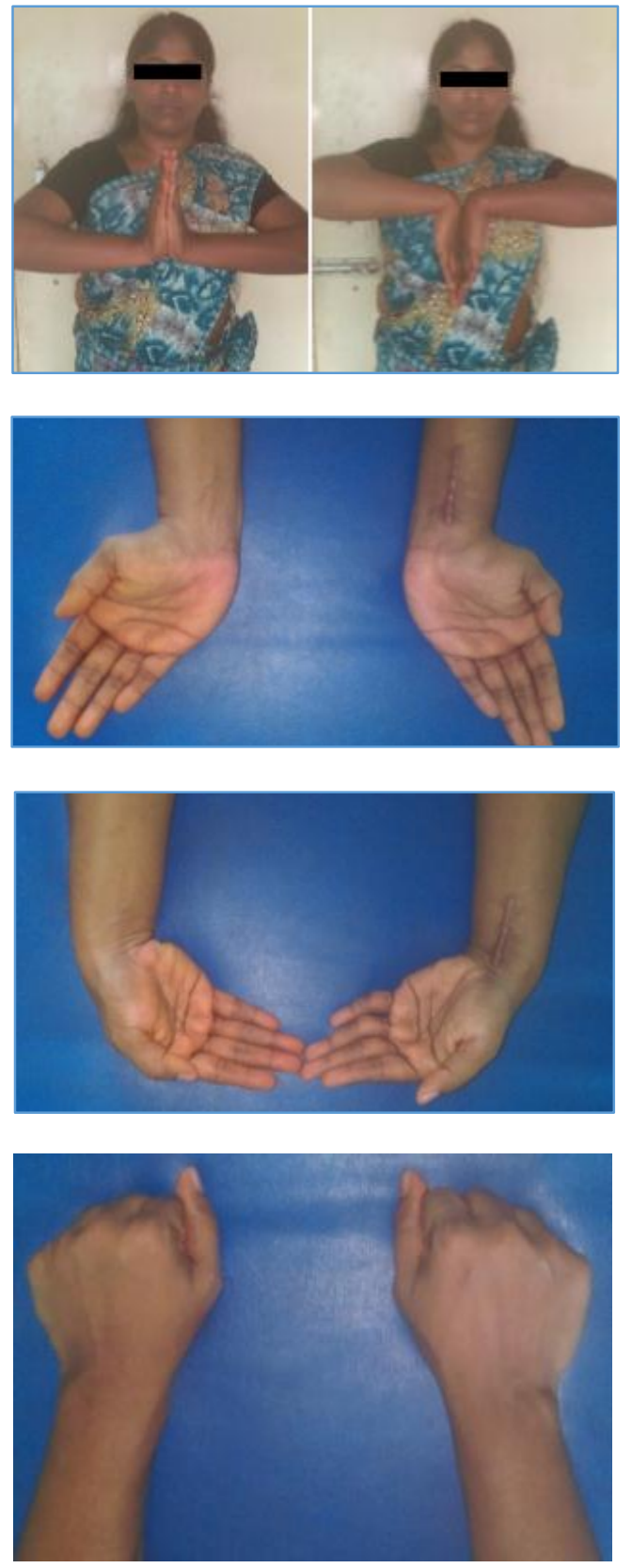

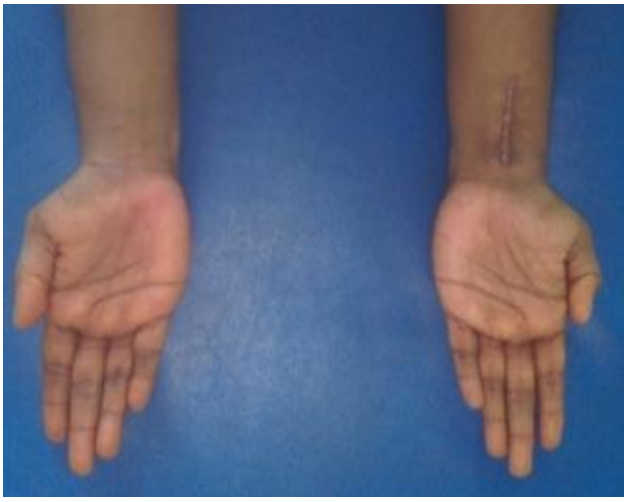

Case 2

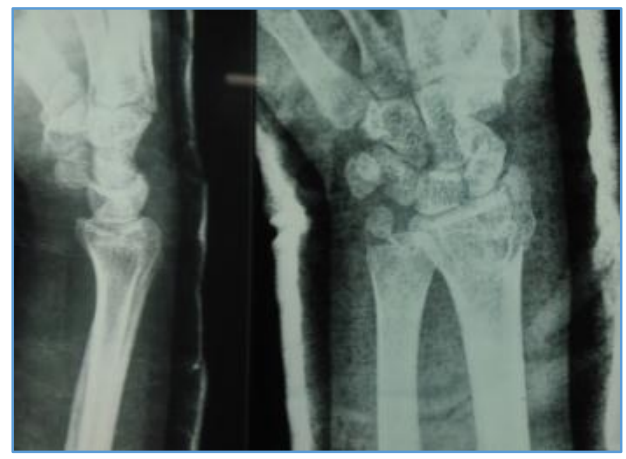

Pre-op X-ray

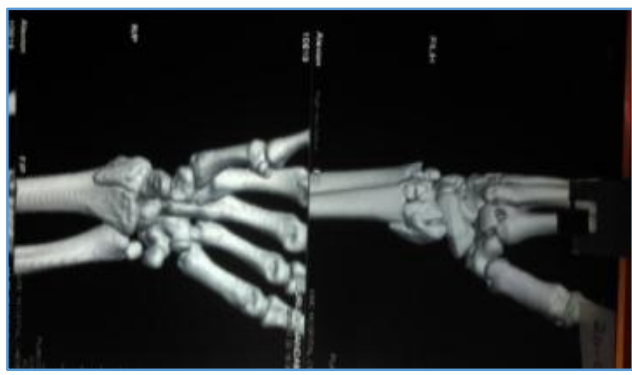

Pre-op CT

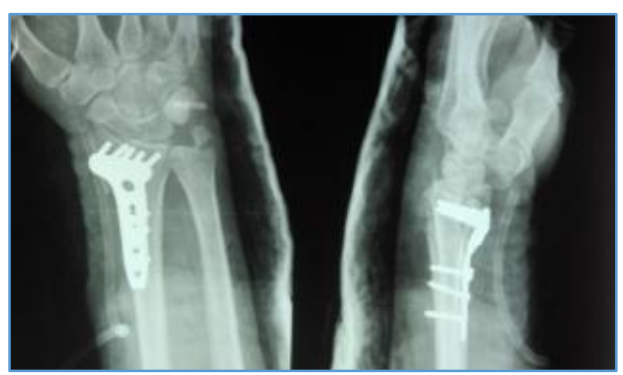

Immediate Post-op X-ray 


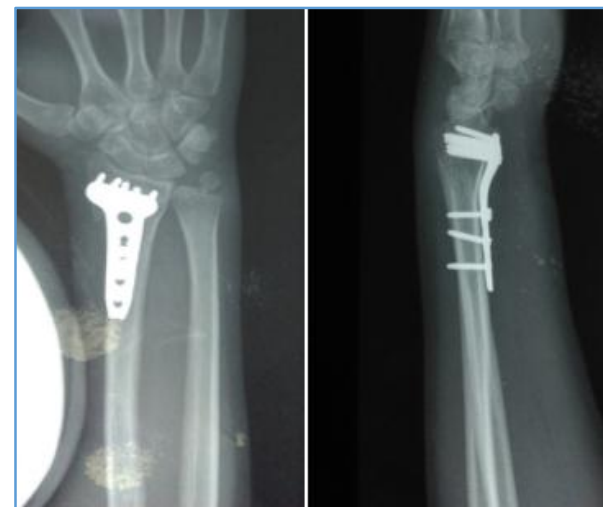

6 Months Followup
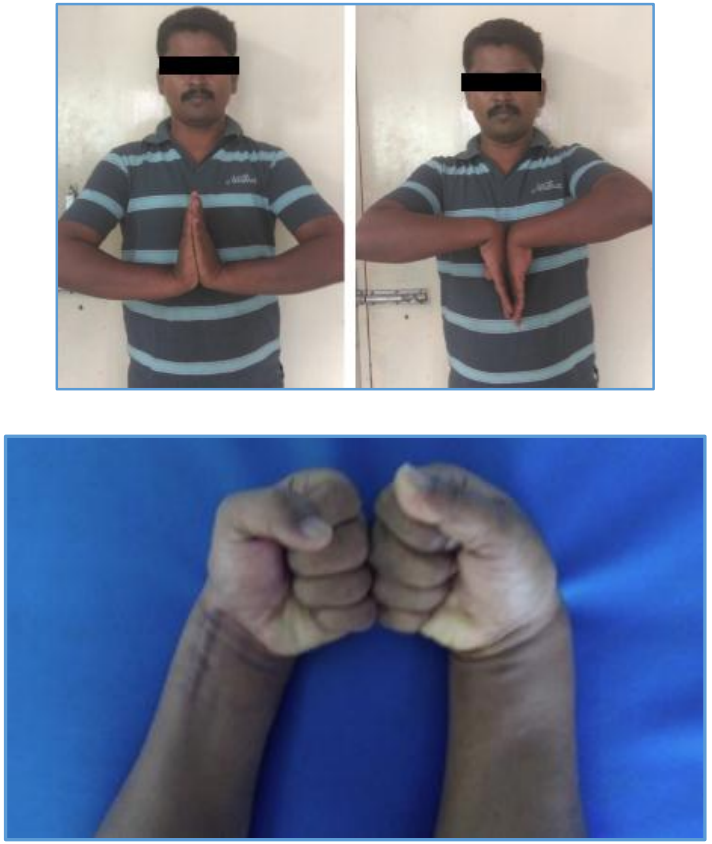

RESULTS

Range of Motion

\begin{tabular}{|c|c|}
\hline Movements & Average (Mean + SD) \\
\hline Palmar flexion & 57.1 with SD 3.5 \\
\hline Dorsiflexion & 63.3 with SD 3.2 \\
\hline Radial deviation & 17.6 with SD 3.0 \\
\hline Ulnar deviation & 24.1 with SD 4.4 \\
\hline
\end{tabular}

At the end of six months, four patients had stiffness of wrist with reduced radial deviation.

\section{Subjective Evaluation}

\begin{tabular}{|c|c|c|}
\hline Symptoms & Score & No. of Patients \\
\hline No pain & 0 & $13(65 \%)$ \\
\hline Occasional pain & 2 & $7(35 \%)$ \\
\hline $\begin{array}{c}\text { Occasional pain with slight } \\
\text { limitation of motion }\end{array}$ & 4 & $0(0 \%)$ \\
\hline $\begin{array}{c}\text { Pain with severe limitation } \\
\text { of motion }\end{array}$ & 6 & $0(0 \%)$ \\
\hline
\end{tabular}

\section{Residual Deformity}

\begin{tabular}{|c|c|c|}
\hline Deformity & Score & No. of Patients \\
\hline Prominent ulnar styloid & 1 & $4(20 \%)$ \\
\hline Residual dorsal tilt & 2 & $0(0 \%)$ \\
\hline Radial deviation of hand & 3 & $0(0 \%)$ \\
\hline
\end{tabular}

Objective Evaluation

\begin{tabular}{|c|c|c|}
\hline Movements & Score & No. of Patients \\
\hline Loss of dorsiflexion & 5 & $0(0 \%)$ \\
\hline Loss of ulnar deviation & 3 & $0(0 \%)$ \\
\hline Loss of supination & 2 & $0(0 \%)$ \\
\hline Loss of palmar flexion & 1 & $0(0 \%)$ \\
\hline Loss of radial deviation & 1 & $4(20 \%)$ \\
\hline Loss of circumduction & 1 & $0(0 \%)$ \\
\hline Pain in DRUJ & 1 & $3(15 \%)$ \\
\hline
\end{tabular}

\begin{tabular}{|c|c|c|}
\hline Result & Score & No. of Patients \\
\hline Excellent & $0-2$ & $15(75 \%)$ \\
\hline Good & $3-8$ & $5(20 \%)$ \\
\hline Fair & $9-20$ & $0(0 \%)$ \\
\hline Poor & $>20$ & $0(0 \%)$ \\
\hline
\end{tabular}

\section{DISCUSSION}

There are many treatment options for distal radius fractures. Non-displaced stable fractures can be treated conservatively with casting. Unstable fractures can be treated with percutaneous K-wire fixation. Comminuted fractures can be treated with external fixation. But there is a period of immobilisation for the wrist joint when treated with external fixation, which can lead to wrist stiffness.(3) There are dynamic external fixators available to treat comminuted distal radius fractures, but the reduction achieved with this method is frequently not satisfactory. Furthermore, reduction of intraarticular fragments could not be achieved to a satisfactory degree with an external fixator.

Open reduction and plating is a very good option to treat comminuted intraarticular fractures of the distal radius. Plates provide stable fixation throughout the entire healing process and also satisfactory articular reduction could be obtained with open reduction.(4) However, the plates available are of fixed designs and may not be suitable for all fracture patterns. Bulky plates especially in the dorsal aspect can cause irritation of tendons, necessitating even implant removal.

Regonazzi introduced the double plating technique for the distal radius using low profile plates at an angulation of 60 degrees to each other.(5) On experimentally induced dorsally tilted distal radius fractures in a cadaver, this method showed superior biomechanical stability when compared to $3.5 \mathrm{~mm}$ $\mathrm{AO}$ ' $\mathrm{T}$ ' locking plate.

Fragment specific fracture fixation is another method to approach distal radius fractures, based on Medoff classification which seeks to address all fragments involved in the distal radius individually and gives rigid fixation to all of them after anatomically aligning them perfectly.(6) This allows immediate wrist mobilisation and reduces chances of stiffness.

The efficacy of fragment specific fracture fixation was initially studied by Dodds et al.(7) They compared fragment specific fracture fixation with augmented external fixation in a experimentally induced comminuted fracture in a cadaver. The biomechanical study showed superior stability in fragment specific fracture fixation in comparison with augmented external fixators.

A study done by Chang et al, where fragment specific fracture fixation was done for a sample of 30 patients with comminuted intraarticular distal radius fractures and 
Gartland and Werley scoring was used to analyse functional outcome showed 13 excellent results, 12 good results and 5 fair results.(8) In our study, we use Gartland and Werley scoring system to assess patients at the end of the study. Among the 20 patients studied, we had 15 excellent reults and 12 good results. The average range of motion achieved in our study far exceeded 10 degrees of palmar flexion and 35 degrees of dorsiflexion, which is essential for activities of daily living.

\section{CONCLUSION}

Hence, we conclude that fragment specific fracture fixation is an excellent method to treat comminuted intraarticular distal radius fractures. We recommend fragment specific fracture fixation for comminuted intraarticular distal radius fractures because of the following advantages-

- Good articular reduction.

- Early mobilisation and rehabilitation.

- Less hardware complications.

- Lesser morbidity.

\section{REFERENCES}

[1] Obert L, Loisel F, Gasse N, et al. Distal radius anatomy applied to the treatment of wrist fractures by plate: a review of recent literature. SICOT J 2015;1:14.

[2] Chang HC, Poh SY, Seah SC, et al. Fragment-specific fracture fixation and double-column plating of unstable distal radial fractures using $\mathrm{AO}$ minifragment implants and Kirschner wires. Injury 2007;38(11):1259-67.
[3] Arora J, Malik AC. External fixation in comminuted, displaced intra-articular fractures of the distal radius: is it sufficient? Arch Orthop Trauma Surg 2005;125(8):536-40.

[4] Peine R, Rikli DA, Hoffmann R, et al. Comparison of three different plating techniques for the dorsum of the distal radius: a biomechanical study. J Hand Surg Am 2000;25(1):29-33.

[5] Maschke SD, Evans PJ, Schub D, et al. Radiographic evaluation of dorsal screw penetration after volar fixed-angle plating of the distal radius: a cadaveric study. Hand (N Y) 2007;2(3):144-50.

[6] Medoff RJ, Kopylov P. Immediate internal fixation and motion of comminuted distal radius fractures using a new fragment-specific fixation system. Orthop Trans 1998;22(1):165.

[7] Dodds SD, Cornelissen S, Jossan S, et al. A biomechanical comparison of fragment-specific fixation and augmented external fixation for intraarticular distal radius fractures. J Hand Surg Am 2002;27(6):953-64.

[8] Zhang C, Zhang ZJ, Wang L, et al. Treatment of type C3 distal radius fractures with AO $2.4 \mathrm{~mm}$ locking plate system after manipulative reduction. Zhongguo $\mathrm{Gu}$ Shang 2014;27(11):965-9. 